Journal of the

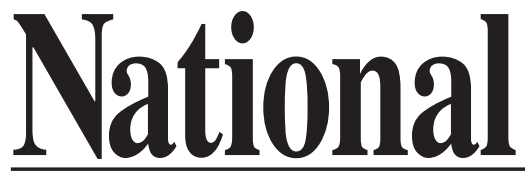

Academy or

Forensic
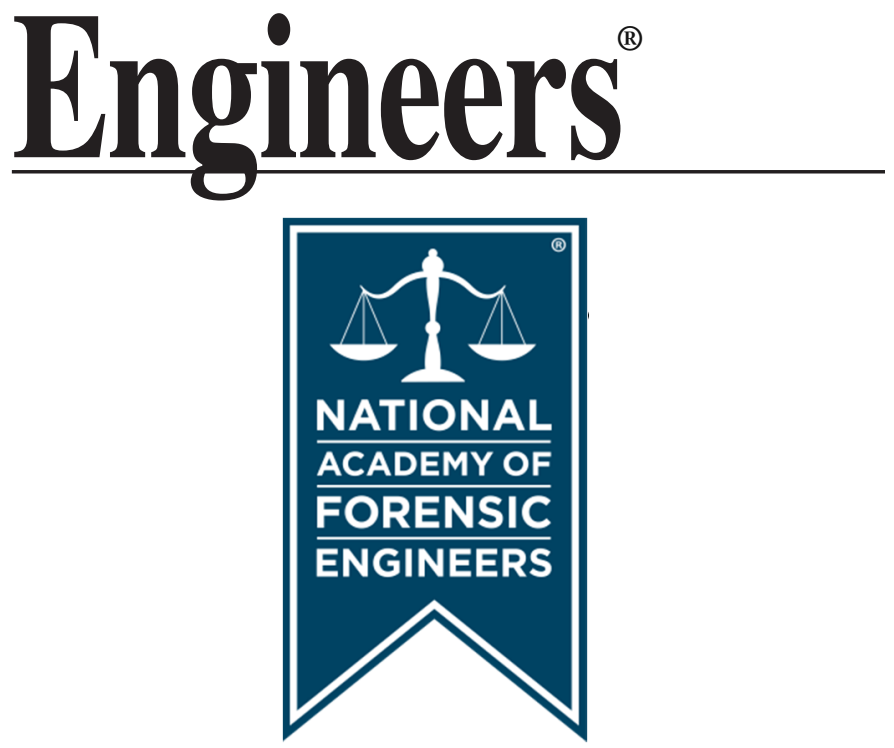

http://www.nafe.org ISSN: 2379-3252 


\title{
Forensic Engineering Analysis of Workplace Exposure to Airborne Contaminants
}

Drew Peake, P.E., CIH, CSP, DEE (NAFE, 460F)

\begin{abstract}
This Forensic Engineering analysis of workplace exposure to airborne contaminants presents three case studies. The common element is that each responds to the generalized complaint that a contaminant is presumed present and therefore presumed to cause harm. The first discusses conditions that an auto mechanic was exposed to while replacing asbestos containing brake linings. The second responds to diagnosed disease resulting from exposure to bioaerosols. The final case regards landlord concerns that airborne contaminants from a printing operation may contaminate the property. The technical basis for responding to these complaints is presented.
\end{abstract}

\section{Asbestos}

Mr. Auto Mechanic worked for a municipal garage in South Carolina from August 1995 through June 1997. His work experience began when he left high school in the ninth grade, and he worked as an auto and truck mechanic at several repair shops and dealers about three and one half years prior to joining the municipality. In all these positions he repaired and replaced brake linings in vehicles as an element of his job. At least some of these brake linings contained asbestos material.

The first indication that this employee was suffering any respiratory distress was when he walked off the job. He had previously used all accrued sick leave, often taking a week or more at a time. Medical excuses for these previous sick leaves were for other ailments relating to gastrointestinal disorders.

Job ticket records indicated that he had worked 290 hours repairing 220 brakes and another 4 hours repairing clutches. An undetermined portion of brake linings and clutch pads contained asbestos. Based on store room inventory of new parts, some undetermined portion of these parts contained asbestos.

Appropriate respirators were made available to all workers, and $\mathrm{Mr}$. Mechanic signed written acknowledgement and instruction regarding receipt 
and use of the safety equipment. However, there is some indication that he was illiterate, and there is no record of verbal instructions.

The wet brush/recycle system was used for brake repair and replacement. An aqueous solution containing an organic solvent is pumped though a filter, directed through a flexible tube and out between the bristles of a brush. (See Figure 1 Wet brush/recycle system.) This provides a gentle flooding of the brake assembly area to wash down dust and perform the necessary cleaning. The solution is captured in a catch pan and is returned to and recirculated from a reservoir.

Mr. Mechanic's physician diagnosed the condition benign asbestos pleural effusion. This was based on clinical tests and patient's reports of work history. The defense physician questioned that diagnosis and noted that the patient has smoked a pack of cigarettes per day for 15 years.

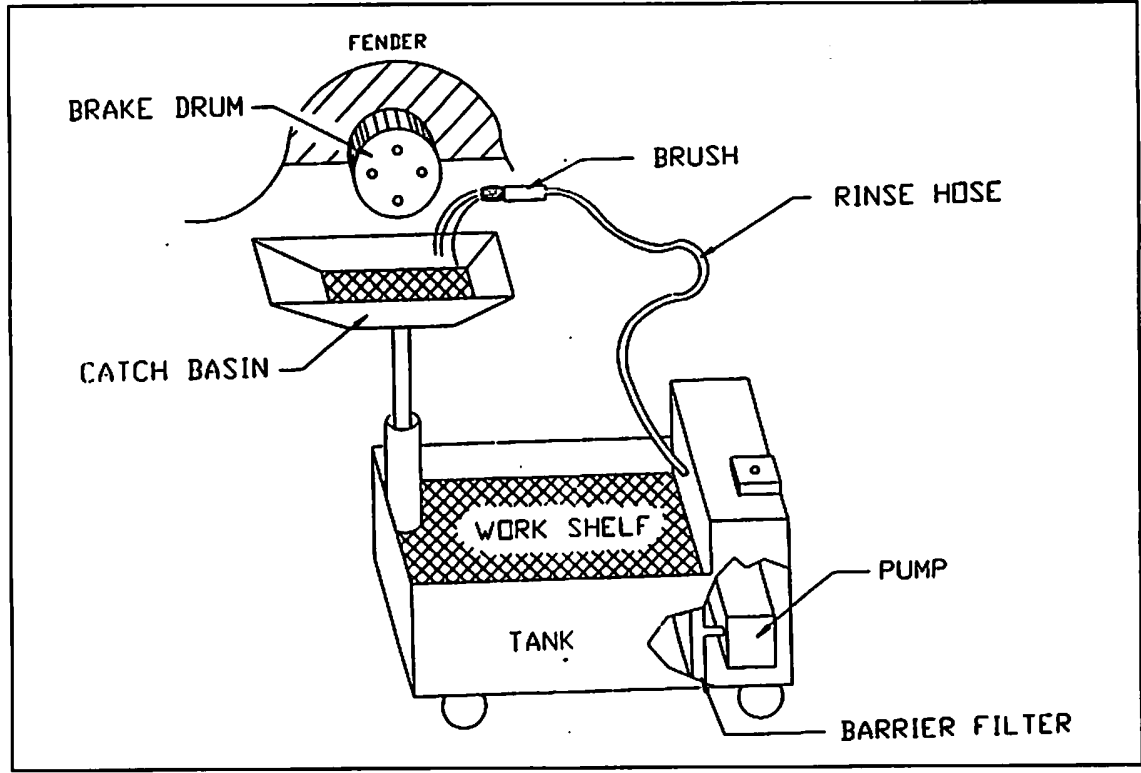

Figure 1

Wet Brush/Recycle System

The Forensic Engineer first visited the site over a year after the last date of employment. A review of standard industry practices and Occupational Safety and Health Administration (OSHA) standards was completed in preparation for this field assessment. One document was particularly relevant. The National Institute of Occupational Safety and Health (NIOSH) is the principal research agency for identifying hazards and making recommendations for regulations. In 1989, NIOSH reported a study of Control of Asbestos Exposure During Brake Drum Service, (NIOSH Publication No. 89-121). 
That report notes that there are earlier studies of airborne asbestos exposure during brake maintenance operations that indicated overexposure. However, when NIOSH performed air monitoring of this operation in numerous locations where various work practices were used, there were no overexposures. Figure 2: graphs the data for various operations, including uncontrolled conditions.

The discrepancy in these data with previous data indicating overexposure reflects the evolution of friction products for vehicular brakes. Woven asbestos was the predominant product for brakes from 1903 to 1930. They typically contained 70 percent or more wire-cored asbestos yarn impregnated with drying oils and bituminous material. By 1940, virtually all automobiles were equipped with molded brake linings. Bonded brake linings were developed in 1948 and soon accounted for 40 percent of the market. The products in current use do not release asbestos fibers in concentrations that are harmful.

The forensic engineer's presentation of this information helped establish Mr. Auto Mechanic's respiratory distress was not likely to have originated or been aggravated by asbestos exposure in the workplace.

Personal Sample Fiver Concentrations: Brake Drum Service, Various Control Methods

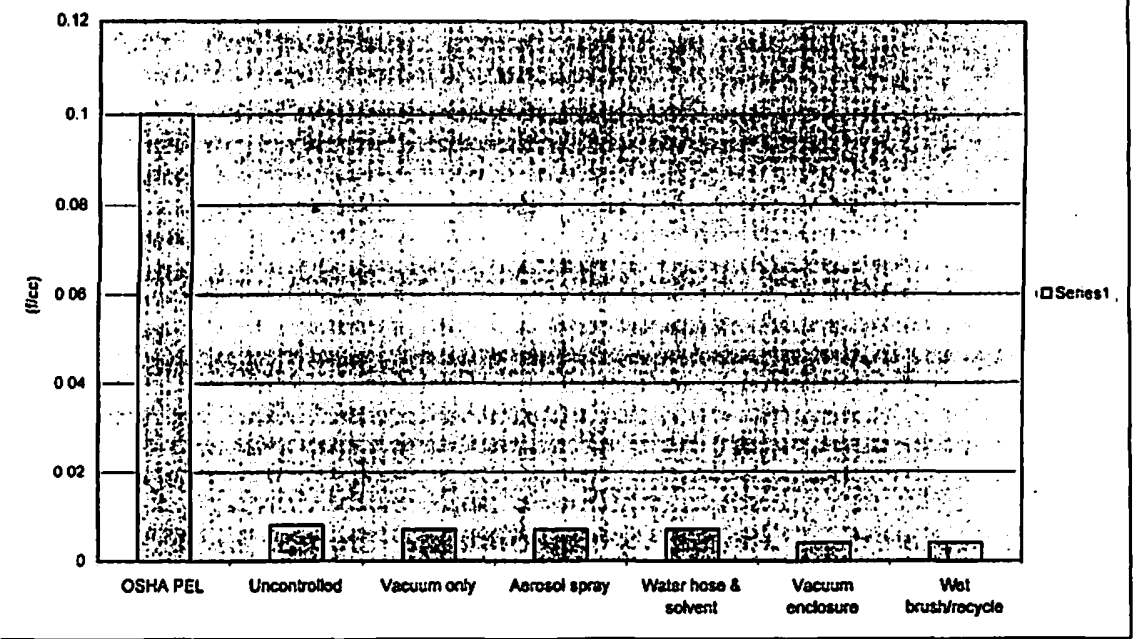

Figure 2

Regulatory Standard/Control Method 


\section{Bioaerosols}

Ms. School Teacher was diagnosed with fibromyalgia and chronic fatigue syndrome. In 1999, she was examined by physicians representing the plaintiff and the defense, both of whom were allergists. They concluded she was severely disabled and likely to remain so. The plaintiff's physician repeatedly referred to a large number of reports from other physicians, and recommended that the diagnosis of fibromyalgia and chronic fatigue syndrome and her resulting disability be performed by a Rheumatologist or Orthopedic Surgeon.

About three years prior, she left her teaching position with a Municipal School System in Florida. Information was not available regarding when her symptoms began. The school investigated her complaint about indoor air quality in March 1994 and again in May 1995. Both investigations suggested the presence of mold and mildew on various surfaces, and offered recommendations for remediation. Ms. School Teacher had not been in the school for at least two years prior to the forensic engineer investigation.

Basic hazard assessment considers the toxicity of a substance along with the probability of exposure. Regardless of the relative toxicity of a substance on a ceiling tile or on the carpet, in the absence of a route of exposure there is little risk. Certainly it can be aesthetically displeasing and suggests that routes of exposure need to be evaluated.

Bioaerosols are airborne microorganisms. They can be sampled and measured. There are various sampling methodologies and analytical protocols. One of the more common draws air through an Anderson Sampler to impinge on various growth media. These are incubated at various temperatures and the biota is classified by microbiologists. The scientific community has not agreed upon an acceptable standard sampling and analysis protocol.

To further complicate matters, the National Institute of Occupational Safety and Health (NIOSH) has evaluated the relative levels of bioaerosols and determined that no correlation is evident between measured values of bioaerosols and disease. NIOSH is the federal research agency that has established Recommended Exposure Levels (REL) for many chemical and physical hazards in the workplace, and uses this information as guidance to the Occupational Safety and Health Administration (OSHA) as they establish Permissible Exposure Levels (PEL).

Ms. School teacher continues to suffer from an alleged exposure to bioaerosols two years after the exposure ceased. Skin test performed by the allergists show sensitivity to the following molds; aspergillus, cladosporium, penicillium, rhodotorula, and two others that are unreadable. Because the class- 
room had been extensively remodeled, the forensic engineer decided that sampling there would not be representative of the previous exposure.

However, since these molds are ubiquitous, the forensic engineer decided there may be some benelit in determining if there was a continuing exposure. Samples were collected in six locations near Ms. School Teacher's home and included locations she was likely to frequent, such as the nearest shopping center parking lot. In each location one or more of aspergillus, cladosporium, penicillium, rhodotorula were present. Based on these data the forensic engineer testified that exposure to the alleged hazard continues.

His recommendation to the defense attorney was that an Occupational Health Physician examine Ms. School Teacher to determine the extent and nature of her illness, and to develop an opinion regarding if and to what extent it was attributable to workplace exposure.

\section{Hazardous Substances}

This final case study describes a tenant-landlord dispute over the potential for property contamination. The lease had strict language concerning releases of hazardous substances to the environment by the tenant. The tenant was a printer who used a high-speed ink jet printer to address mailings in bulk. The ink contained methyl ethyl ketone (MEK), some of which evaporated into the manufacturing space.

During a meeting at the print shop with the property owners representative and his technical expert, it was resolved that concerns about MEK contact with the building could be eliminated by installing barriers to prevent any spillage to the floors or walls.

The unresolved concern was that airborne MEK released from the plant might be scrubbed out of the air by precipitation. The vast majority of rainfall would runoff into the stormwater conveyance, where it would be further diluted by the combined stormwater flow.

However, the outdoor pavement is beginning to deteriorate as evidenced by visible cracks. The concern was expressed that rainfall in equilibrium with the gas phase of MEK would settle in these cracks and lead to soil concentrations of MEK above levels that would trigger Georgia Hazardous Site Response Act ${ }^{1}$ notification (0.79 PPM MEK).

Air samples were collected by the forensic engineer, a Certified Industrial Hygienist. In the opinion of the plant manager, two samples represent "worst case" operating scenarios (DD-01 AND DD-03). The third sample (DD-02) repre- 
sented up-set conditions that would not continue long before a decision was made to shutdown the equipment and call the equipment vendor. Samples DD-01 and DD-02 were collected at the equipment-working surface. Sample DD-03 was collected at the loading dock door at the end of the day. The highest concentration measured was $70 \mathrm{mg} / \mathrm{m}^{3} \mathrm{MEK}$.

This datum was used in the following analysis. The concentration (70 $\mathrm{mg} / \mathrm{m}^{3} \mathrm{MEK}$ ) represents a mole fraction of $2.17 \times 10^{-5}$. This value is developed as follows:

1. For an ideal gas under Universal Scientific Standard Conditions, $1 \mathrm{~kg}$ Mole occupies a volume of $22.4 \mathrm{~m}^{3}$.

2. One $\mathrm{kg}$ Mole of MEK weighs $72.1 \mathrm{~kg}$.

3. The concentration of a $\mathrm{kg}$ Molc is $\left(72.1 \mathrm{~kg} / 22.4 \mathrm{~m}^{3}=3.22 \mathrm{~kg} / \mathrm{m}^{3}=\right.$ $3.22 \times 10^{6} \mathrm{mg} / \mathrm{m}^{3}$.

4. The Mole fraction is approximately $\left(70 \mathrm{mg} / \mathrm{m}^{3} / 3.22 \times 10^{6} \mathrm{mg} / \mathrm{m}^{3}\right)=$ $2.17 \times 10^{-5}$.

This mole fraction will dissolve in water to a maximum theoretical concentration of $0.424 \mathrm{mg} / \mathrm{l}(0.424 \mathrm{PPM})$. This value is developed as follows:

1. Henry's law states that at constant temperature the solubility of a gas in a liquid is directly proportional to the pressure of the gas above the liquid. This is represented by the relationship,

$$
\mathrm{N}=\mathrm{KP}
$$

Where

$\mathrm{N}$ is the molar concentration in liquid (g mole/liter),

$P$ is the partial pressure of the gas (ATM), and

$\mathrm{K}$ is the Henry's law constant ( $\mathrm{K}$ for MEK is 3.69

ATM $/$ mole frac $=0.271$ mole frac $/$ ATM $)^{2}$

2. The partial pressure of MEK is approximately $2.17 \times 10^{-5}$ atmospheres, as follows:

(Mole fraction) $($ Total pressure $)=$ partial pressure

$\left(2.17 \times 10^{-5}\right)(1 \mathrm{ATM})=2.17 \times 10^{-5} \mathrm{ATM}$ 
3. Therefore, the maximum potential molar concentration of $M E K$ in the liquid phase is $5.88 \times 10^{-6}$, as follows:

$$
\mathrm{N}=\mathrm{KP}
$$

$5.88 \times 10^{-6} \mathrm{~g}$ mole $/$ liter $=(0.271 \mathrm{~mole}$ frac $/ \mathrm{ATM})\left(2.17 \times 10^{-5} \mathrm{ATM}\right)$

4. This becomes $0.424 \mathrm{mg} / \mathrm{l}$ and $0.424 \mathrm{PPM}$, as follows:

$$
424 \times 10^{-6} \mathrm{~g} / \mathrm{liter}=\left(5.88 \times 10^{-6} \mathrm{~g} \text { mole } / \mathrm{liter}\right)(72.1 \mathrm{~g} / \mathrm{gram} \text { mole })
$$

$$
424 \times 10^{-6} \mathrm{~g} / \text { liter }=0.424 \mathrm{mg} / \mathrm{liter}
$$

Thus, the theoretical limit to MEK concentration in rainwater is well below the reportable concentration. As rainwater evaporates, MEK will release to the atmosphere to maintain equilibrium. Thus, MEK in rainwater will not concentrate in the soil. These calculations are based on MEK concentrations in air that are not likely to be exceeded with expanded operations over a larger area or by increased production rates in the same area.

The practical limit is considerably lower, and provides an exceptional margin of safety. Factors that inhibit reaching the theoretical limit include:

- Insufficient time for equilibration. Terminal settling velocity for a raindrop can be in excess of 10 meters/second. Rain will be in contact with airborne MEK only as it passes through the approximately three meter vertical distance near the loading dock door. The scrubbing of MEK is not likely to be complete in less than $\mathbf{3 0 0}$ milliseconds in a single pass.

- Insufficient concentrations. As rain falls through the zone of influence, some MEK will be removed from the air. This will reduce the concentration in the air. As the airborne concentration of MEK is reduced, there is less available to dissolve in the rain. During a rain event, it would be reasonable to expect nondetectable concentrations of MEK in rainfall just a few meters away from the loading dock door.

- As air moves away fiom the loading dock, the concentration of MEK will diminish exponentially as described by the Gaussian dispersion model. At the beginning of a rain event, the maximum concentrations of MEK in air will be at the loading dock. The resulting concentration of MEK in raindrops will be similarly distributed, as concentration decreases exponentially with distance away from the loading dock. 
- Any time the concentration in raindrops exceeds equilibrium, some MEK will be released to reestablish equilibrium. As the concentration of MEK in air is reduced by scrubbing or with distance, there will be an imbalance in equilibrium with MEK concentration in raindrops that will result in off gassing to reestablish equilibrium. This will result in lower concentrations in rain.

- Rain from outside the zone of intluence will dilute rain that has passed through the airborne MEK.

- The deterioration of the pavement is less than one percent. Rainfall on 99 percent of the pavement will flow to the stormwater conveyance where it will combine with other stormwater that has not been in contact with MEK. The combined stormwater will be diluted well below concentrations that could be of concern. This stormwater will flow by gravity off the property without impacting soils.

- Rainfall that does not run off to stormwater conveyance will evaporate or absorb into the ground. That portion which evaporates will release MEK as it evaporates to establish equilibrium well below levels of concern. That fraction that is absorbed has been demonstrated to be below levels of regulatory concern, and will be further diluted by any moisture in the soil. It is not physically or chemically possible for the concentration to accumulate.

While this information was convincing to all parties, the dispute encouraged the tenant to look for alternatives. The printer has relocated to a larger space in a better location and a lower rental. This analysis was used to convince the new landlord that no environmental lerms were necessary in the lease.

\section{Conclusion}

Responding to claims of workplace exposure to airborne contaminants can involve a wide range of technical skills.

\section{References}

1. Official Code of Georgia Annotated (O.C.G.A.) $§ 12-8-90$ et seq. (1992). as amended.

2. Carl L. Yaws, et.al., "Using Solubility and Henry's Law Constant Data for Ketones in Water", Pollution Engineering, 1998. 